When Opposites Attract? Exploring the Existence of Complementarity in Self-Brand Congruence Processes

\title{
AUTHORS
}

\author{
Maria Karampela \\ University of Strathclyde \\ 199 Cathedral Street, Glasgow, G4 0QU, United Kingdom \\ maria.karampela@strath.ac.uk, +44 (0)141 5483243
}

\begin{abstract}
Angela Tregear
University of Edinburgh

29 Buccleuch Place, Edinburgh, EH8 9JS, United Kingdom

angela.tregear@ed.ac.uk, +44 (0)1316513855

\author{
Jonathan Ansell
}

University of Edinburgh

29 Buccleuch Place, Edinburgh, EH8 9JS, United Kingdom

jake.ansell@ed.ac.uk, +44 (0)1316503806
\end{abstract}

\section{Susan Dunnett}

University of Edinburgh

29 Buccleuch Place, Edinburgh, EH8 9JS, United Kingdom susan.dunnett@ed.ac.uk, +44 (0)1316503814 


\title{
When Opposites Attract? Exploring the Existence of Complementarity in Self-Brand Congruence Processes
}

\begin{abstract}
In the psychology of human interpersonal attraction, complementarity is a well-recognized phenomenon, where individuals are attracted to partners with different but complementary traits to their own. Although scholarship in human-brand relations draws heavily from interpersonal attraction theory, preferred techniques for measuring self-brand congruence tend to capture it in only one form: the similarity configuration, which expresses the extent to which brand traits essentially resemble or mirror a consumer's own. Hence, the aim of this study is to explore, for the first time, the existence of complementarity in self-brand congruence. From a canonical correlation analysis of survey data in which respondents rated their own personality traits and those of their favorite brand, the existence of both similarity and complementarity configurations is indeed revealed. Based on this, the study then derives a measure of self-brand congruence that captures both configurations, and tests its predictive power for a range of brand-related outcomes. The new measure is found to perform well against existing measures of self-brand congruence based purely on a similarity configuration, particularly for emotionally based brand-related outcomes.
\end{abstract}

\section{KEYWORDS}

Self-brand congruence; brand personality; interpersonal attraction; complementarity; social exchange theory, brand choice 


\section{INTRODUCTION}

Academics and managers alike continually seek improved explanations of why consumers engage with some brands more than others. Since the seminal works by Sirgy (1982) and Aaker (1997), self-brand congruence ${ }^{1}$ and brand personality have become important explanatory concepts, with numerous empirical studies supporting the premise that consumers invest brands with human personality traits and are drawn to brands with traits that align judiciously with their own (Birdwell, 1968; Branaghan \& Hildebrand, 2011;

Dolich, 1969; Huang, Mitchell, \& Rosenbaum-Elliott, 2012; Malär, Krohmer, Hoyer, \& Nyffenegger, 2011; Sirgy, 1985; Stern, Bush, \& Hair, 1977); they also tend to evaluate them more favorably (Graeff, 1996a, 1997). Self-brand congruence research continues to be a very active field, with recent contributions in this journal alone exploring aspects such as the antecedents of the concept (Quester, Plewa, Palmer, \& Mazodier, 2013) and the extent to which it applies to different settings or product categories (Antón, Camarero, \& Rodríguez, 2013).

In terms of conceptual underpinning, the self-brand congruence literature draws heavily from the psychology of human interpersonal attraction, in particular the theory that individuals are attracted to one another via a process of comparison between the perceived characteristics or traits that they possess and those of the desired partner. In practice, interpersonal psychologists have long recognized that the precise alignment of traits between partners can take different forms, from the similarity configuration (where attraction between two individuals is derived from a direct resemblance or mirroring of their characteristics), to the complementarity configuration (where attraction derives from mutually different, but complementary traits of two relationship partners). Although complementarity has proven powerful in explaining various aspects of human interpersonal attraction (Dryer \& Horowitz, 1997), and its existence has been suggested in a branding context (Heath \& Scott, 1998; 
Swaminathan \& Dommer, 2012), to date it has been completely overlooked in self-brand congruence empirical research, in favor of similarity. Arguably, a key reason for the dominance of similarity in a branding context is the preferred use of direct techniques to empirically measure self-brand congruence, which involve asking consumers to rate directly the extent to which they feel a brand aligns with their own characteristics, often in a global, holistic sense (Malär et al., 2011; Sirgy et al., 1997). Such techniques have limited capacity to reveal or explore alternative patterns of trait alignment, and as a result, the assumption is perpetuated that self-brand congruence involves purely a similarity configuration of traits. In light of the above, the current study has three main objectives. First, it undertakes an original exploration of the existence of alternative forms of trait alignment in self-brand congruence, with a specific focus on complementarity. Second, it contributes a novel method of measuring self-brand congruence, by developing and applying a technique which allows both complementarity as well as similarity to be captured in consumer-brand trait alignment. Finally, it tests the predictive power of this new measure against two similarity-based congruence measures for a range of desirable brand-related behaviors. Through these objectives, the study develops self-brand congruence theory by offering a new way of conceptualizing trait alignment patterns, and also makes a managerial contribution by offering a new practical technique for measuring self-brand congruence in the field. Furthermore, the paper provides an in-depth discussion and exploration of how complementarity effects might become more salient in different purchase or consumption situations, including different product categories. This discussion opens new areas for further research that can frame the conditions under which complementarity alignments become more or less prevalent.

The remainder of the article is organized as follows. First, the meaning of congruence and its link to attraction are explained in the branding and interpersonal contexts, respectively. Next, 
a review is undertaken of self-brand congruence measurement techniques. Both these sections culminate in a statement of relevant hypotheses. Thereafter, the methods and results of the empirical study are presented, including explanation of the new congruence measure, and outcome of tests of its predictive powers. The article then discusses the results and concludes with limitations and directions for future research, with a specific focus on the different configurations of product categories and consumption situations where complementarity effects could materialize, and hence are worth exploring further.

\section{LITERATURE REVIEW AND HYPOTHESES DEVELOPMENT}

\section{Congruence and Attraction in Branding and Interpersonal Contexts}

In the thirty plus years since it was first proposed, self-brand congruence has become amongst the most widely accepted explanations both of initial consumer attraction to brands, as well more enduring attachment and loyalty. Taking the perspective of brands as relationship partners (Fournier, 1998) to which human-like personality traits are ascribed (Aaker, 1997), the theory proposes that when judging brands, consumers undertake a process of psychological comparison between a brand's characteristics or meanings and their own self-concepts, which leads to a perception of congruence between the two (Malhotra, 1988; Sirgy, 1982). In practice, self-brand congruence has been associated with numerous desirable brand-related outcomes such as positive brand attitudes/evaluations (Graeff, 1997), as well as brand preference, loyalty and emotional attachment (Bellenger, Steinberg, \& Stanton, 1976; Kressmann et al., 2006; Malär et al., 2011), making this concept a key phenomenon of interest to brand managers as well as scholars. 
However, for the concept to have explanatory and predictive power, the mechanism by which consumers compare brand traits with their own requires careful reflection. As indicated earlier, similarity is the mechanism that has become most widely accepted in the self-brand congruence literature to date. That is, congruence is believed to represent the extent to which brand traits directly resemble or mirror a consumer's own. Following this, consumer attraction to a brand represents the extent to which the brand directly reflects the consumer's own sense of themselves, exemplified by the maxim 'birds of a feather flock together'. For instance, based on this perspective, a consumer that perceives himself/herself as gentle and caring may be more likely to choose Dove products, as this brand portrays such characteristics. Studies which have adopted this popular conceptualization of the basis of self-brand congruence include, for example, Barone, Shimp, and Sprott (1999); Birdwell (1968); Branaghan and Hildebrand (2011); Dolich (1969); Grubb and Hupp (1968); Jamal and Al-Marri (2007); Lam, Ahearne, Mullins, Hayati, and Schillewaert (2013); Landon (1974); Puzakova, Kwak, and Rocereto (2009); Sirgy (1985); Stokburger-Sauer, Ratneshwar, and Sen (2012). The concept of similarity certainly has merit in a branding context, and studies which examine the link between self-brand congruence (conceptualized as similarity of traits) and outcomes such as brand attraction and loyalty do find some positive results (Bellenger et al., 1976; Kressmann et al., 2006; Malär et al., 2011). However, given the range of relationship types consumers can have with brands - e.g. 'flings', 'courtships' or 'casual friends' in Fournier's (1998) typology - it would seem surprising that in all cases the relationships are underpinned by a mirroring mechanism, whereby the brands in question only reflect aspects of the consumers' own traits or self-concepts. A 'courtship' type of relationship, for example, could feasibly represent an attraction where the brand in question offers quite different traits to a consumer's own. To explore this possibility further, the article 
now turns to the body of work which has heavily inspired theory in self-brand congruence: the psychology of human interpersonal attraction.

Social exchange theory has been widely used to explain the main underlying mechanism of human interpersonal attraction. Originally developed by Homans $(1958,1961,1974)$, the theory proposes that relationships are mutual exchanges of rewards that are of value to each party (Berscheid \& Walster, 1978; Blau, 1964; Cropanzano \& Mitchell, 2005; Emerson, 1976; Foa \& Foa, 1980; Gouldner, 1960). The more valuable rewards are to individuals, the more individuals will be attracted to others perceived as offering these rewards. Crucially, a key source of reward in human relationships is the extent of alignment in partners' personal characteristics (e.g. opinions, values, personality traits). This alignment may exhibit one of two types of configuration: similarity or complementarity (Gross, 1987; Martin, Carlson, \& Buskist, 2007).

As indicated above, similarity refers to alignments where relationship partners' personal characteristics directly mirror each other (Montoya, Horton, \& Kirchner, 2008). An example here would be an attraction forming between two individuals who are both shy and reflective in nature. Similarity has been found to satisfy partners' needs for self-validation and social approval (Aron, Steele, Kashdan, \& Perez, 2006). Similarity also seems particularly salient to attraction in the early stages of a relationship, as it helps partners to feel safe and familiar with each other (Klohnen \& Luo, 2003), and sense that their interactions will be smooth and pleasant (Berger \& Calabrese, 1975; Dryer \& Horowitz, 1997; Rubin, 1973).

On the other hand, the complementarity configuration refers to alignments where relationship partners' characteristics are different from each other, but in a complementary way (reflected in the maxim 'opposites attract' ${ }^{\prime 2}$ (Winch, 1958). An example would be an attraction forming between two individuals, one of whom is outgoing and extrovert, the other quiet and introspective. Complementarity has its logic in the concept of self-expansion (Aron \& Aron, 
1986), which proposes that association with others who have different perspectives or characteristics leads to personal enhancement or growth (Aron \& Aron, 1986; Aron, Aron, Tudor, \& Nelson, 1991; Aron, Norman, Aron, McKenna, \& Heyman, 2000; Aron et al., 2006; Klohnen \& Luo, 2003). Hence, attraction inspired by complementarity may be explained as individuals being drawn to partners to access characteristics that they desire but do not possess themselves, for self-enhancement purposes. Complementarity may be particularly salient to attraction as a relationship endures over time, as once relationships become established, it is the complementary needs and traits of individuals that often contribute most to a partnership's robustness (Kerckhoff \& Davis, 1962; Winch, 1958). Importantly, the interpersonal attraction literature also emphasizes that similarity and complementarity are not necessarily mutually exclusive mechanisms of attraction, such that individuals can be drawn to one another when each possesses some similar, and some complementary, traits or characteristics (Dryer \& Horowitz, 1997; Furnham \& Tsoi, 2012).

Overall, these insights have important implications for consumer-brand relations and selfbrand congruence in particular. Social exchange theory provides a compelling explanation for how and why consumers initiate, sustain or dissolve relationships with brands (Fournier, 1998), and also an explanation of the underlying mechanism of consumer attraction to brands, via the concept of trait comparison and alignment (Dolich, 1969; Malhotra, 1988; Sirgy, 1982). It is perhaps all the more surprising, therefore, that forms of trait alignment other than similarity have been so overlooked in the self-brand congruence literature to date. The lack of exploration of complementarity is particularly puzzling because of numerous branding situations where this form of alignment appears to be exhibited. For example, consider the conspicuous use of brands in public and social situations: in at least some cases, this practice represents consumer appropriation of meanings or associations from brands, which consumers do not feel they possess themselves, for social fulfilment outcomes (Escalas 
\& Bettman, 2003). The basis of consumer attraction to brands in such circumstances therefore appears to be complementarity-seeking, not similarity-seeking. Another example is enduring consumer-brand relationships, where consumer engagement with brands involves aspects of self-enhancement or growth (Fournier, 1998). Following interpersonal attraction theory, which holds that a contrasting configuration of traits is particularly salient in longer term partnerships (Kerckhoff \& Davis, 1962), complementarity would again appear to be a strong possibility. In summary, therefore, this study proposes that complementarity exists in self-brand congruence, and may be particularly represented in more enduring consumerbrand relationships. Hence:

H1: Self-brand congruence may exhibit a complementarity configuration.

H2: Complementarity configurations are more likely in longer-term consumerbrand relationships.

\section{Measuring Self-Brand Congruence}

Any measure of self-brand congruence requires development of an appropriate scale of trait items to represent human and brand personality (HP and BP) respectively, and identification of a suitable technique to measure the congruence between them. In BP research, various bespoke scales have been devised, of which Aaker's (1997) scale is arguably the most popular (Eisend \& Stokburger-Sauer, 2013). This proposes that there are 42 personalityrelated meanings that consumers attach to brands, loading ultimately onto five higher order dimensions (Sincerity, Excitement, Competence, Sophistication and Ruggedness). Despite its popularity however, and advantage of having items derived specifically from BP meanings, Aaker's scale has been criticized for its inclusion of non-personality traits (Azoulay \& Kapferer, 2003), while its ability to adequately capture HP traits is also unproven (Bosnjak, Bochmann, \& Hufschmidt, 2007; Huang et al., 2012; Sweeney \& Brandon, 2006). In an 
alternative approach, BP researchers have directly applied scales developed by HP psychologists, most notably the Five-Factor Model (FFM). This proposes that HP traits are organized into five higher order dimensions: Extraversion, Agreeableness, Conscientiousness, Emotional Stability and Openness (Costa Jr \& McCrae, 1992). Decades of empirical study confirm that the FFM is a very reliable HP measurement scale (Nevid \& Pastva, 2014; Schmitt, Allik, McCrae, \& Benet-Martínez, 2007), and recent research also indicates that it can be meaningfully applied to explain BP structure (Huang et al., 2012). The current study therefore employed the FFM model to measure HP and BP.

Techniques for measuring self-brand congruence also generally fall into one of two categories: direct measures and discrepancy scores. Direct measures involve asking research participants directly the extent to which they feel a brand (or typical brand user) is consistent with themselves, typically in a global, holistic sense (Malär et al., 2011; Sirgy et al., 1997). Direct measures have the advantage of using respondents' own perceptions of congruence to derive the measure, contemplated in a naturalistic way, which authors argue improves the reliability of the results (Sirgy et al., 1997). However, direct measures are problematic for examining alternative configurations of trait alignment, because the approach of asking respondents to rate how much a brand is consistent with themselves, or a version of themselves, effectively constrains the investigation to the similarity configuration. Given the objective of the current research to explore complementarity, direct measurement techniques were therefore deemed unsuitable.

The alternative approach to measuring self-brand congruence is the discrepancy score technique. This involves recording respondents' perceptions of their own personality (HP) on a range of trait items, recording their perceptions of a brand's personality (BP) on the same items, mathematically computing a discrepancy score for each dimension, based on an index, and then summing the scores across all dimensions. The resulting scores represent the 
magnitude of the difference between respondents' HP and BP ratings, hence the degree of congruence can be interpreted. Although subject to some criticisms (Sirgy et al., 1997), this technique has arguably greater scope for examining the nuances of trait alignment patterns, as respondents systematically rate all trait items relevant for the research. Furthermore, although traditional discrepancy score formulas, as described above, only capture a similarity configuration, they can be modified to allow for other configurations to be revealed. Hence, the discrepancy score technique was chosen to measure self-brand congruence in this study, incorporating an adjustment to capture the existence of complementarity between HP and BP traits. Overall, the study proposes that because this modified measure allows for the possibility of both similarity and complementarity configurations, it will have greater predictive power for desirable brand-related behaviors. Hence the third hypothesis is:

H3: A measure of self-brand congruence which captures a complementarity configuration of HP and BP traits has greater predictive power than measures based solely on a similarity configuration.

\section{METHODOLOGY}

\section{Sample}

To test the hypotheses, an online survey was conducted on students enrolled at a UK business school. Students represent a rich source of data for self-brand congruence research, due to a tendency for high involvement and active experimentation with brands (Moore, Wilkie, \& Lutz, 2002), to reinforce and project identities that are in a high state of flux (Chernev, Hamilton, \& Gal, 2011). The relatively strong interest of this population in the subject matter 
of the study also enhances data reliability (Bryman, 2008; Dillman, Smyth, \& Christian, 2009; Fowler, 2009).

Two hundred and six students took part in the survey. Two email reminders were sent and a small charitable donation was pledged for each completed questionnaire. The profile of the final sample was: $36 \%$ male and $64 \%$ female; $57 \%$ aged $17-22,43 \%$ aged 23 and over; $54 \%$ undergraduate and $46 \%$ postgraduate. Given the unequal number of female and male respondents, a series of tests was conducted on responses to check for significant differences. No statistically significant differences were found.

\section{Design \& Measures}

The first part of the questionnaire measured respondents' perceptions of their own HP. To do this, the 40-item mini-marker scale of the FFM (Saucier, 1994) was employed, which is widely recognized as a reliable and valid instrument for measuring human personality (Dwight, Cummings, \& Glenar, 1998; Mooradian \& Nezlek, 1996). Respondents rated how accurately each of the 40 items described themselves as a person, on a 7-point scale $(1=$ "extremely inaccurate", 7= "extremely accurate"). To reduce fatigue, the items were presented over two screens.

The questionnaire then addressed respondents' brand relationships and BP perceptions. To measure the latter, the peer rating method was adopted (Huang et al., 2012), which involves inviting respondents to refer to a self-chosen favorite brand, rather than to one pre-selected by the researcher. In this way, the study investigates brand relationships that are relevant and meaningful to respondents, which increases the reliability of the analysis. For this research, respondents were asked to nominate their favorite brand from one of two purchase categories - clothing or technology - which had been pre-identified as particularly relevant to students in exploratory interviews preceding the survey. Respondents were then asked a range of 
questions on their relationship with their chosen brand, including their perceptions of quality, satisfaction, love, intuitive fit and loyalty. These responses comprised the brand-related outcome measures of the analysis, employed to test H3. These concepts were measured using existing scales from previously published studies, specifically those of Batra, Ahuvia, and Bagozzi (2012), Carroll and Ahuvia (2006), Quester and Lim (2003), and Eisingerich and Rubera (2010). Then, respondents rated the BP traits of their favorite brand on the same 40item scale as for HP, as this scale has also been established as reliable and valid for measuring brand personality (Huang et al., 2012). Specifically, respondents were asked to consider their favorite brand as a person and to rate the accuracy of each of the items as descriptors, on the same 7-point scale as before.

Finally, respondents indicated the extent to which their favorite brand reflected their actual and ideal selves respectively ( $1=$ strongly disagree, $7=$ strongly agree), using the 2 -item scales of Malär et al. (2011). Hence, actual self-brand congruence was measured using two items ("The personality of my favorite brand is consistent with how I see myself" and "The personality of my favorite brand is a mirror image of me"), and ideal self-brand congruence was also measured with two items ("The personality of my favorite brand is consistent with how I would like to be" and "The personality of my favorite brand is a mirror image of the person I would like to be"). These items comprised the similarity-based self-brand congruence measures to be tested for predictive power against the newly derived measure.

\section{RESULTS}

Composition of Human and Brand Personality Scores 
In order to investigate self-brand congruence and test for the existence of complementarity, the first step was to explore the composition of respondents' HP and BP in the sample, that is, the personality traits respondents attached to themselves and those they attached to their nominated favorite brand. A principal component analysis (PCA) with Varimax rotation was therefore conducted on respondents' $\mathrm{HP}$ and $\mathrm{BP}$ ratings. In the PCA of the HP ratings, KMO (.770) was satisfactory, Bartlett's test of sphericity was statistically significant $(\mathrm{p}<.05)$, and MSA values were above .50 , indicating that the variables were adequately correlated. As recommended for the sample size of this study, a cut-off value of .40 was applied to the traitto-factor loadings (Hair, Black, Babin, \& Anderson, 2010; Mooi \& Sarstedt, 2011), leading to the successive deletion of 3 traits. This led to a 5-factor solution for HP, explaining $50.7 \%$ of the variance. Table 1 summarizes the solution and composition of factors, and it can be seen that all items loaded exactly as expected for the FFM (Saucier, 1994).

(Insert Table 1 about here)

The same process was followed to analyze respondents' BP ratings. In this PCA, adequate correlation between variables was again confirmed $(\mathrm{KMO}=.807$; Bartlett's, $\mathrm{p}<.05$; MSA values $>.50$ ). Following the successive deletion of 9 items with insignificant loadings (cut-off .40), a 5-factor solution was also derived, which explained 51.3\% of variance. Table 2 summarizes the solution and composition of the factors, including the allocated factor labels.

(Insert Table 2 about here)

Comparing Tables 1 and 2, it can be seen that although the BP and HP constructs have common features, some key differences are also exhibited. On the one hand, the BP 
dimensions labelled Practicality, Friendliness and Dynamism have much in common with the HP factors of Conscientiousness, Agreeableness and Extraversion, respectively, as they are comprised mainly of items from these HP dimensions. However, the BP factor of Reflectiveness represents a reduced, more cerebral version of HP Openness, being comprised only of the items 'philosophical' and 'deep'. Yet the most striking difference between HP and BP dimensions relates to the remaining BP factor, labelled here Emotional Instability. It is comprised entirely of the unfavorable items of HP Emotional Stability ('envious', 'jealous', 'moody', 'temperamental'), plus all the negatively inflected items from the other HP dimensions (e.g. 'sloppy', 'careless', 'unsympathetic', 'harsh'). It seems therefore that when respondents considered the personality traits of their favorite brands, they evaluated the unfavorable traits in a way that was exclusive of the other dimensions, rather than associating each negatively inflected trait with its corresponding dimension, which was the pattern exhibited in the HP ratings. Table 3 presents a summary of both the HP and BP dimensions, respectively.

(Insert Table 3 about here)

\section{Configuration Between Human and Brand Personality Scores}

In order to test the configuration between human and brand personality, a canonical correlation analysis (CCA) was conducted on respondents' HP and BP scores. CCA is highly appropriate for investigations that seek to understand the relationship between two sets of multiple variables (Alpert \& Peterson, 1972; Sherry \& Henson, 2005). It also minimizes the risk of committing Type 1 errors, as the relationship between these sets is assessed simultaneously rather than with multiple statistical tests (Hair et al., 2010; Joshanloo, Rastegar, \& Bakhshi, 2012; Mai \& Ness, 1999; Sherry \& Henson, 2005). By applying a 
linear equation to the observed variables in the sets (known as the predictor and criterion set, respectively), CCA generates a synthetic variable for each set (Hair et al., 2010; Holbrook \& Moore, 1982; Schinka, Dye, \& Curtiss, 1997; Sherry \& Henson, 2005). Successive canonical functions (pairs of equations) are then computed so as to yield the maximum possible correlation between the synthetic variables (Mazzocchi, 2008). Inspection of the canonical correlation coefficients (loadings) for each canonical function gives an indication of the strength of relationship between the sets of variables (Hair et al., 2010). As successive canonical functions are based on residual variance, all canonical functions are orthogonal (Hair et al., 2010).

For the current study, the unit of analysis was each respondent's HP and BP factor scores, summed from their raw ratings of the original $40 \mathrm{HP}$ and $40 \mathrm{BP}$ items: this is recommended to remove any multicollinearity (Mazzocchi, 2008). The factor scores relating to the five HP dimensions constituted the predictor variable set in the analysis, whilst those relating to the five BP dimensions constituted the criterion set. The analysis was conducted using the MANOVA command in SPSS syntax. The full model was statistically significant (Wilks' $\lambda=$ $.534, \mathrm{~F}(25,729.61)=5.38, \mathrm{p}<.001)$, explaining $46.6 \%$ of shared variance from five functions with squared canonical correlations $\left(\mathrm{R}_{\mathrm{c}}{ }^{2}\right)$ of $.278, .184, .050, .035$ and .011 , respectively. As the first two functions explained large proportions of the variance $(27.8 \%$ and $18.4 \%$, respectively), and were significant when tested, they were examined further. Table 4 presents the summary statistics for these two functions, showing which variables from the predictor (HP) and criterion (BP) sets contribute significantly to each one (cut-off .40 , in bold).

(Insert Table 4 about here) 
It can be seen from Table 4 that three variables contributed significantly to Function 1: HP Agreeableness and HP Emotional Stability from the predictor set, and BP Emotional Instability from the criterion set. This is a striking result. It indicates that the more that respondents rated themselves as warm and emotionally well-balanced, the more they rated their favorite brand as having markedly opposing traits (i.e. capricious, neurotic), and vice versa. Importantly therefore, Function 1 clearly exhibits a complementarity configuration of HP and BP traits, thus H1 is supported. For Function 2, again there are three significant variables: HP Openness and HP Extraversion from the predictor set, and BP Reflectiveness from the criterion set. A noteworthy aspect of this function is that HP Extraversion has a negative loading. The result indicates that the more respondents rated themselves as intellectually open, quiet and introverted, the more their favorite brands were rated as philosophical and deep, and vice versa. Function 2 therefore exhibits a similarity configuration of HP and BP scores. The stability of the canonical functions was examined by extracting a random sub-sample from the dataset and performing a subsequent CCA. This produced a statistically significant full model (Wilks' $\lambda=.534, \mathrm{~F}(25,451.00)=3.32, \mathrm{p}<$ .001 ) with two significant functions exhibiting the same variables and configurations as the original analysis. Hence, the stability of the original functions was supported.

\section{Development of the New Self-Brand Congruence Measure}

The final step of the study was to derive and test a new measure of self-brand congruence which captures both complementarity and similarity configurations of HP and BP traits. As described previously, existing indirect measures of self-brand congruence involve computing a discrepancy score for each HP and BP dimension, based on an index, and then summing the scores across all dimensions. However, as this technique is only able to capture a similarity configuration of traits, an original modification was applied here. Specifically, a predicted 
score was computed for each $\mathrm{BP}$ factor $\left(\mathrm{pBP}_{\mathrm{i}}, \mathrm{i}=1 \ldots 5\right)$, by taking the statistically significant canonical correlation coefficients of the $\mathrm{BP}(\mathrm{i}=1 \ldots 5)$ and $\mathrm{HP}\left(\mathrm{HP}_{\mathrm{j}}, \mathrm{j}=1 \ldots .5\right)$ scores, multiplying these by the relevant HP scores, and summing them. This can be represented as:

$$
\mathrm{pBP}_{\mathrm{i}}=\sum_{\mathrm{j}=1}^{5} \mathrm{w}_{\mathrm{ji}} \mathrm{HP}_{\mathrm{j}}
$$

where $\mathrm{w}_{\mathrm{ji}}$ is the statistically significant coefficient for $\mathrm{j}^{\text {th }} \mathrm{HP}$ score $\left(\mathrm{HP}_{\mathrm{j}}\right)$ for the $\mathrm{i}^{\text {th }} \mathrm{BP}$ score $\left(\mathrm{BP}_{\mathrm{i}}\right)$, derived from the CCA. The congruence discrepancy scores $\left(\mathrm{DS}_{\mathrm{i}}, \mathrm{i}=1 \ldots 5\right)$ were then computed as the difference between respondents' observed $\mathrm{BP}$ factor scores $\left(\mathrm{BP}_{\mathrm{i}}, \mathrm{i}=1 \ldots 5\right)$ and their predicted BP factor scores, as described above. This can be expressed as:

$$
\mathrm{DS}_{\mathrm{i}}=\mathrm{BP}_{\mathrm{i}}-\mathrm{pBP}_{\mathrm{i}} \text { for } \mathrm{i}=1, \ldots, 5
$$

Hence, the new measure of self-brand congruence comprises five discrepancy scores for each respondent, one for each BP factor ${ }^{3}$. A small discrepancy score (closer to zero) signifies a high degree of self-brand congruence, a large score (either negative or positive) indicates a low degree of congruence. This measure was used to test $\mathrm{H} 2$ and $\mathrm{H} 3$.

\section{Test of Trait Configuration and Brand Relationship Length}

For $\mathrm{H} 2$, the study sought to establish whether complementarity configurations are more likely in longer-term brand relationships. To do this, respondents were split into two sub-samples based on the self-reported length of relationship they had experienced with their favorite brand (below 3 years, 3 years and over). An independent samples t-test was then performed on respondents' discrepancy scores to ascertain whether the scores for respondents in the long relationship group were significantly smaller (therefore denoting stronger HP-BP congruence) than those in the short relationship group. Although inspection of the pooled variance estimates revealed that long relationship respondents did indeed exhibit smaller discrepancy scores, the difference was not significant $[\mathrm{t}(204)=.932$ for DS BP Emotional 
Instability, $\mathrm{t}=.405$ for DS BP Practicality, .058 for DS BP Dynamism, .084 for DS BP Friendliness, .948 for DS BP Reflectiveness, all with $\mathrm{p}>.05]$. Hence, H2 is not supported.

\section{Testing the Predictive Power of the New Measure of Self-Brand Congruence}

For H3, the study sought to test the predictive power of the newly derived measure of selfbrand congruence on a range of desirable brand-related outcomes. These outcomes are commonly studied in the consumer behavior literature and previous research has, to some extent, examined them in the context of self-brand congruence. Specifically, with the exception of current loyalty and separation distress, which were metric in nature (hence linear regression was used), all outcomes were tested using discriminant analysis. In all cases, the brand-related outcomes were inputted successively as the dependent variables ${ }^{4}$, and the new discrepancy scores inputted as independent variables. These tests were then performed again, with participants' gender, category of their favorite brand and length of brand relationship inputted as additional independent variables alongside the discrepancy scores. All these tests were repeated in a final round, substituting the new discrepancy scores with the two similarity-based measures of actual and then ideal self-brand congruence by Malär et al. (2011). To compare the predictive powers of the three measures (new discrepancy scores, actual self-brand congruence and ideal self-brand congruence), for each test result an inspection was made of the significance of the model, the percentage of variance explained (represented by $1-$ Wilks' $\lambda$ ), and - in the case of the discriminant tests - the percentage of cases correctly classified.

Based on these criteria, there were six brand-related outcomes for which the new congruence measure performed better: perceptions of brand quality, intuitive fit, passion, pleasure, resistance to negative word of mouth and separation distress. For one outcome - overall love for the brand - the new measure performed comparably with both the actual and ideal self- 
brand congruence measures only capturing similarity, whilst for two outcomes - frequent thoughts about the brand, and contribution of the brand to life meaning - the actual self-brand congruence measure was a better predictor. For the remaining six outcomes, none of the measures had predictive power (satisfaction, trust, willingness to forgive brand transgressions, positive word of mouth, and current and future loyalty to the brand). Overall, these results indicate that the predictive power of the new self-brand congruence measure compares very well with the two similarity-based measures, hence H3 receives good support.

\section{GENERAL DISCUSSION \& IMPLICATIONS}

This study sought to explore the existence of a complementarity configuration of traits in self-brand congruence and to derive and test a measure of congruence that captures both complementarity and similarity configurations. Whilst evidence of a similarity configuration is also found, the results from the analysis here clearly demonstrate, for the first time, the existence of a complementarity configuration between respondents' personality traits and those of their favorite brands. There are both conceptual and methodological implications from this finding, each discussed separately below.

\section{Theoretical Implications}

The study indicates that the 'opposites attract' phenomenon previously only identified in human interpersonal attraction extends also to human-brand interactions. As such, it supports the perspective of brands as active relationship partners (Fournier, 1998), by providing evidence that not only do brands reinforce consumers' existing traits, but can also act as vehicles through which consumers access desired traits that they do not think they currently have, in order to achieve certain goals. In interpersonal psychology, the phenomenon of 
complementarity is linked specifically to goals of self-enhancement and growth (Aron \& Aron, 1986; Aron et al., 1991; Aron et al., 2000; Aron et al., 2006; Kerckhoff \& Davis, 1962; Klohnen \& Luo, 2003). In fact, this explanation fits quite well the specific combination of HP and BP traits making up the complementarity configuration of self-brand congruence found in this study (HP Agreeableness, HP Emotional Stability and BP Emotional Instability). As commented earlier, this configuration indicates that individuals who see themselves as warm and emotionally well-balanced tend to have favorite brands that they perceive as capricious, neurotic and rebellious, whilst individuals who see themselves as temperamental and socially awkward attach themselves to brands they perceive as warm and efficacious. Hence, what may be exhibited here is growth or enhancement of individuals' identities and social selves through playful or serious experimentation with brands with some opposing traits.

The revealing of the existence of a complementarity configuration leads to reflection on the many possible consumption scenarios and settings where a complementarity alignment might become more salient or important, extending the theoretical implications. We discuss four alternatives below.

First, the extent to which a consumption situation is public vs private appears to have a fundamental role to play in the salience of complementarity, as has already been highlighted in previous literature (Graeff, 1997). On the one hand, consumers might feel less interested or constrained about the brands they choose to engage with in private settings, and might be more prone to brands that resemble their selves (similarity). Yet, there are private consumption situations where complementarity effects might become prominent, such as in the case of a mother from an economically vulnerable background purchasing Pampers toddler products that are more expensive than other similar brands. In this consumption situation, the selection of this particular brand can be viewed as a form of compensatory consumption and might be attributed to the consumer's need to reduce feelings of self- 
deficiency (Mandel, Rucker, Levav, \& Galinsky, 2017): the mother chooses to buy a brand with characteristics and connotations that will supplement her self-portrait as a 'proper', devoted, and caring mother (complementarity). In a similar vein, complementarity is also exhibited in private consumption settings when consumers choose brands for experimentation purposes: a consumer choosing a set of Victoria's Secret lingerie to add boldness, mysteriousness, and playfulness to an otherwise bashful personality.

On the other hand, complementarity might be particularly salient to a number of public and social consumption situations, for various reasons that demonstrate a more strategic consumer mindset. In social interactions, both online and offline, consumers might choose to associate with brands that add to their self-perceptions in a complementary way, for impression management, or again, deficiency correction and compensatory consumption reasons. For instance, previous research has documented that consumers engage in selfie posing and posting to impress upon others a certain image of themselves (Pounders, Kowalczyk, \& Stowers, 2016). In this sense, posing for a selfie with a Chanel bag can be interpreted as an effort by the consumer to project characteristics such as class and sophistication that the consumer might not currently possess. Similarly, opting for a glass of single malt Macallan whisky (in contrast to a regularly-preferred Johnnie Walker brand) at a meeting of potential business partners may also be attributed to complementarity-seeking behavior: the consumer in this case may seek to supplement their projected personality by adding to it, through the particular brand selection, more complex, sophisticated, and intellectual traits that would be viewed as valuable characteristics for a business partner.

Beyond the private vs public nature of the consumption situation, other purchase occasions might also be motivated by complementarity-seeking behaviors. As mentioned earlier, complementarity alignments might materialize in certain consumer-brand relationships, where consumer engagement with brands involves aspects of self-enhancement or growth 
(Fournier, 1998). For instance, in the typology proposed by Fournier, consumer-brand relationships such as flings, courtships, or secret affairs, imply the presence of characteristics in the brand partner that the consumer does not own (e.g. Vicki's range of shampoo brands pg. 357 of the Fournier article - which allows the consumer to select each time the shampoo brand that will enable her to become "the kind of person" she wants to be that particular day). Furthermore, brand preference and choice that manifest complementarity-seeking behavior accords with existing theory on consumer self-motivation in general, and goal orientation in particular. Specifically, theory proposes that individuals compare themselves to others and present different aspects of themselves mainly due to three self-motives (Sedikides \& Strube, 1997): self-assessment (the need to reach the truth about the self), self-verification (the need to find/filter information, or interact with people/objects, that will confirm/reinforce our sense of self), and self-enhancement. The latter self-motive - representing our need to either seek information/interaction with people/objects that will allow us to project flattering images of ourselves (self-advancement), or to avoid those that will highlight our less positive aspects (self-protection) - has been shown to be the strongest motivation (Sedikides, 1993). Under this lens, complementarity-seeking behavior is consistent with consumers' efforts to associate with brands that supplement their personalities with favorable traits. Similarly, complementarity alignments might manifest themselves when consumers seek to fulfil social goals, such as entering specific groups and communities. A specific example here might be the selection of brands to project a more aggressive or assertive personality in order to join a particular sports club).

\section{Methodological Implications}

The results of this study confirm that the underlying patterns of trait alignment in self-brand congruence can take different forms, of which mirroring is only one. As existing measures of 
self-brand congruence are similarity-based, their inability to capture a greater spectrum of nuance in trait alignment patterns may well reduce their predictive power for a range of desirable brand-related behaviors. In future, studies adopting indirect measures of self-brand congruence (i.e. discrepancy score techniques) may therefore consider employing a canonical correlation analysis and discrepancy score calculation adjustment similar to the one presented here. For studies investigating self-brand congruence through direct measures, which rely upon respondents being asked directly the extent to which they feel a brand is consistent with themselves, typically in a global, holistic sense, approaches may be modified in two ways to capture non-similarity configurations. First, disaggregated response categories may be employed so that data are captured at the level of dimensions or individual items rather than (or in addition to) a global evaluation. This would expand the number and potential range of characteristics under consideration, thereby improving the scope of the analysis to capture nuances in alternative trait configurations. Second, direct measures studies could incorporate questions to respondents that address explicitly the possibility of complementarity configurations in self-brand congruence, rather than just similarity. An example of appropriate phrasing for such a question could be: "If this brand was a person, how much would it complement your personality?"

\section{Limitations \& Areas for Future Research}

The paper concludes with reflections on study limitations and avenues for future research. First, the study was conducted on a student sample. Although this was appropriate for the exploratory nature of the research - as students are well-recognized as active builders of social identity, and often have heightened consciousness of, and engagement with, brand meanings - the specific self-brand trait configurations found here may not be replicable in the wider population. The use of a student sample may also be a reason for the lack of correlation 
found between self-brand congruence (as measured by the new discrepancy scores) and length of brand relationship (H2). Specifically, it is possible that the youthful profile of the respondents prevented sufficient representation of longer-term, enduring brand relationships in the sample. Finally, respondents were asked to complete the questionnaire for their favorite brand in one of two product categories - clothing or technology - both of which had been identified as most relevant during a qualitative study prior to this study. However, these product categories are both high involvement-thinking/feeling in nature (Ratchford, 1987), hence it remains unclear whether complementarity configurations exist in product types where consumers show less involvement.

As a result, the authors see many avenues for future research. First, as generally recommended (Pham, 2013), future work could explore whether the results of this study are replicable in different contexts, product categories, and demographic groups. For instance, future studies may explore the existence of complementarity in populations with a wider age profile, in particular investigating whether it is a greater feature of self-brand congruence in brand relationships enduring over many years. Moreover, in interpersonal contexts, it has been shown that the characteristics that are perceived as crucial to be shared/complemented in the first stages of a relationship are not always the same as those which partners think should be shared/complemented later on (Luo \& Klohnen, 2005). This includes not only personality traits, but also values and beliefs. Hence this raises the question as to whether there are specific brand characteristics that need to be similar/complementary to those of the consumer at different stages of relationship development.

Perhaps the most fruitful area for further research is a more comprehensive exploration of the conditions under which complementarity becomes more salient. The discussion above has highlighted a number of consumption occasions where complementarity configurations might materialize. The authors consider that the conspicuousness of the consumption situation 
(private vs public) has particular significance, especially given the mixed results of previous research on the link between conspicuousness and similarity-based self-brand congruence (Dolich, 1969; Graeff, 1996a, 1996b, 1997). What might also deepen understanding of the conditions under which complementarity alignments emerge, is the consideration of alternative combinations of different consumption situations and product categories. This is because the importance of similarity-based self-brand congruence has been documented to vary, depending on the product category examined each time (Malhotra, 1988). This line of research could be informed by goal-priming techniques that can reveal how consumers' goal orientations might moderate the strength with which complementarity and similarity configurations prevail.

In a similar vein, another interesting avenue would be to investigate whether the presence of independent or interdependent self-construal (Markus \& Kitayama, 1991) influences whether complementarity or similarity alignments are exhibited. Previous research $(\mathrm{Wu}, \mathrm{Cutright}, \&$ Fitzsimons, 2011) has shown that consumers with independent selves opted for magazine brands which they had previously assessed as having completely opposite personality traits (in terms of competence and excitement) to their own. Hence, further insights could be revealed about the conditions under which complementarity manifests itself by comparing consumers with independent or interdependent self-construal. Studies of this kind should take account of the fact that these effects might be moderated by the cultural context and influences in which the consumption behavior is embedded: certain cultures have been shown to exhibit much more susceptibility to interpersonal influence - therefore implying a greater need for deficiency correction or compensatory consumption from complementarity configurations than in other cultures (Gentina, Shrum, \& Lowrey, 2016).

Finally, future research could explore the predictive power of the new measure for outcomes where the effects of self-brand congruence might be moderated by other variables (e.g. 
loyalty) - as has been found by previous studies using similarity-based measures (He \& Mukherjee, 2007; Ibrahim \& Najjar, 2008; Park \& Lee, 2005).

In conclusion, the authors propose that the current research enhances understanding of the alignment processes between consumer and brand personality, by demonstrating that there are some self-brand congruence contexts where opposites do indeed attract. In such contexts, alignment measures incorporating complementarity configurations are advantageous, particularly where the objective is to predict emotionally based brand-related outcomes. 


\section{Footnotes}

${ }^{1}$ This is also referred to as 'self-congruity', 'image congruence', or 'self-image congruence' by various scholars (Hohenstein, Sirgy, Herrmann, \& Heitmann, 2007; Hosany \& Martin, 2012; Kressmann et al., 2006; Sirgy et al., 1997). It is distinct from 'functional congruity', which refers to consumers' performance expectations about the brand (Hohenstein et al., 2007).

${ }^{2}$ The authors use this maxim in a colloquial sense for the purposes of illustrating complementarity in this paper. They acknowledge that the interpersonal attraction literature in fact distinguishes opposite traits configurations in three forms: ideal-self similarity, dissimilarity, and complementarity (Klohnen \& Luo, 2003; Wetzel \& Insko, 1982). In a complementarity configuration, some of a partner's characteristics may be opposing, but in a compensatory way.

${ }^{3}$ To illustrate, for BP Emotional Instability:

First, the statistically significant coefficients for each of the five HP scores were identified in the CCA results. This process showed that four of the five coefficients were statistically significant (BP Emotional Instability<-> HP Conscientiousness, BP Emotional Instability<$>$ HP Agreeableness, BP Emotional Instability $<->$ HP Extraversion, and BP Emotional Instability <-> HP Emotional Stability; BP Emotional Instability $<->$ HP Openness was not statistically significant).

The significant coefficients were multiplied by respondents' respective HP factor scores (HP Conscientiousness, HP Agreeableness, HP Extraversion, and HP Emotional Stability), and the products were summed to derive the predicted score for BP Emotional Instability (BP1). Discrepancy score for BP Emotional Instability $(\mathrm{BP} 1)=$ Observed BP Emotional Instability (BP1) factor score - Predicted BP Emotional Instability (BP1) factor score

${ }^{4}$ The fifteen outcomes were: perceptions of brand quality; satisfaction; trust; current loyalty; future loyalty intentions; intuitive fit with the brand; passion; pleasure; overall love; distress from potential separation; willingness to forgive potential transgressions; frequency of thoughts about the brand; perceived contribution/importance of the brand to life meaning; engagement in positive word-of-mouth; and resistance to negative comments made by others about the brand. 


\section{REFERENCES}

Aaker, J. (1997). Dimensions of Brand Personality. Journal of Marketing Research, 34(3), $347-356$.

Alpert, M. I., \& Peterson, R. A. (1972). On the Interpretation of Canonical Analysis. Journal of Marketing Research, 9(2), 187-192.

Antón, C., Camarero, C., \& Rodríguez, J. (2013). Usefulness, Enjoyment, and Self-Image Congruence: The Adoption of e-Book Readers. Psychology \& Marketing, 30(4), 372384.

Aron, A., \& Aron, E. (1986). Love and the Expansion of Self: Understanding Attraction and Satisfaction: Hemisphere Publishing Corporation.

Aron, A., Aron, E. N., Tudor, M., \& Nelson, G. (1991). Close Relationships as Including Other in the Self. Journal of Personality and Social Psychology, 60(2), 241-253.

Aron, A., Norman, C. C., Aron, E. N., McKenna, C., \& Heyman, R. E. (2000). Couples' Shared Participation in Novel and Arousing Activities and Experienced Relationship Quality. Journal of Personality and Social Psychology, 78(2), 273-284.

Aron, A., Steele, J. L., Kashdan, T. B., \& Perez, M. A. X. (2006). When Similars Do Not Attract: Tests of a Prediction From the Self-Expansion Model. Personal Relationships, 13(4), 387-396.

Azoulay, A., \& Kapferer, J.-N. (2003). Do Brand Personality Scales Really Measure Brand Personality? Journal of Brand Management, 11(2), 143-155.

Barone, M. J., Shimp, T. A., \& Sprott, D. E. (1999). Product Ownership as a Moderator of Self-Congruity Effects. Marketing Letters, 10(1), 75-85.

Batra, R., Ahuvia, A., \& Bagozzi, R. P. (2012). Brand Love. The Journal of Marketing, $76(2), 1-16$ 
Bellenger, D. N., Steinberg, E., \& Stanton, W. W. (1976). The Congruence of Store Image and Self Image as it Relates to Store Loyalty. Journal of Retailing, 52(1), 17-32.

Berger, C. R., \& Calabrese, R. J. (1975). Some Explorations in Initial Interaction and Beyond: Toward a Developmental Theory of Interpersonal Communication Human Communication Research, 1(2), 99-112.

Berscheid, E., \& Walster, E. H. (1978). Interpersonal Attraction (2nd ed.): Reading, Mass.: Addison-Wesley Pub. Co.

Birdwell, A. E. (1968). A Study of the Influence of Image Congruence on Consumer Choice. Journal of Business, 41(1), 76-88.

Blau, P. M. (1964). Exchange and Power in Social Life. New York: J. Wiley.

Bosnjak, M., Bochmann, V., \& Hufschmidt, T. (2007). Dimensions of Brand Personality Attributions: A Person-Centric Approach in the German Cultural Context. Social Behavior and Personality: an international journal, 35(3), 303-316.

Branaghan, R. J., \& Hildebrand, E. A. (2011). Brand personality, self-congruity, and preference: A knowledge structures approach. Journal of Consumer Behaviour, 10(5), 304-312.

Bryman, A. (2008). Social Research Methods (3rd ed.). Oxford: Oxford University Press.

Carroll, B. A., \& Ahuvia, A. C. (2006). Some Antecedents and Outcomes of Brand Love. Marketing Letters, 17(2), 79-89.

Chernev, A., Hamilton, R., \& Gal, D. (2011). Competing For Consumer Identity: Limits to Self-Expression and the Perils of Lifestyle Branding. Journal of Marketing, 75(3), 6682.

Costa Jr, P. T., \& McCrae, R. R. (1992). NEO PIR-R ${ }^{\mathrm{TM}}$ - Revised NEO Personality Inventory (NEO PI-RTM) and NEO Five-Factor Inventory (NEO-FFI) - Professional manual. Odessa, FL: Psychological Assessment Resources. 
Cropanzano, R., \& Mitchell, M. S. (2005). Social Exchange Theory: An Interdisciplinary Review. Journal of Management, 31(6), 874-900.

Dillman, D. A., Smyth, J. D., \& Christian, L. M. (2009). Internet, Mail, and Mixed-Mode Surveys: The Tailored Design Method (3rd ed.). Hoboken, N.J.: Wiley \& Sons.

Dolich, I. J. (1969). Congruence Relationships Between Self Images and Product Brands. Journal of Marketing Research, 6(1), 80-84.

Dryer, D. C., \& Horowitz, L. M. (1997). When Do Opposites Attract? Interpersonal Complementarity Versus Similarity. Journal of Personality \& Social Psychology, 72(3), 592-603.

Dwight, S. A., Cummings, K. M., \& Glenar, J. L. (1998). Comparison of Criterion-Related Validity Coefficients for the Mini-Markers and Goldberg's Markers of the Big Five Personality Factors. Journal of Personality Assessment, 70(3), 541-550.

Eisend, M., \& Stokburger-Sauer, N. E. (2013). Measurement Characteristics of Aaker's Brand Personality Dimensions: Lessons to be Learned from Human Personality Research. Psychology \& Marketing, 30(11), 950-958.

Eisingerich, A. B., \& Rubera, G. (2010). Drivers of Brand Commitment: A Cross-National Investigation. Journal of International Marketing, 18(2), 64-79.

Emerson, R. M. (1976). Social Exchange Theory. Annual Review of Sociology, 2, 335-362.

Escalas, J. E., \& Bettman, J. R. (2003). You Are What They Eat: The Influence of Reference Groups on Consumers' Connections to Brands. Journal of Consumer Psychology, 13(3), 339-348.

Foa, U. G., \& Foa, E. B. (1980). Resource Theory: Interpersonal Behavior As Exchange. In K. J. Gergen, M. S. Greenberg, \& R. H. Willis (Eds.), Social Exchange: Advances in Theory and Research (pp. 77-94). New York; London: Plenum Press. 
Fournier, S. (1998). Consumers and their brands: Developing relationship theory in consumer research. Journal of Consumer Research, 24(4), 343-373.

Fowler, F. J. (2009). Survey Research Methods (4th ed.). London: Sage Publications.

Furnham, A., \& Tsoi, T. (2012). Personality, Gender, and Background Predictors of Partner Preferences. North American Journal of Psychology, 14(3), 435-454.

Gentina, E., Shrum, L. J., \& Lowrey, T. M. (2016). Teen attitudes toward luxury fashion brands from a social identity perspective: A cross-cultural study of French and U.S. teenagers. Journal of Business Research, 69(12), 5785-5792. doi:10.1016/j.jbusres.2016.04.175

Gouldner, A. W. (1960). The Norm of Reciprocity: A Preliminary Statement. American Sociological Review, 25(2), 161-178.

Graeff, T. R. (1996a). Image Congruence Effects on Product Evaluations: The Role of SelfMonitoring and Public/Private Consumption. Psychology and Marketing, 13(5), 481499.

Graeff, T. R. (1996b). Using Promotional Messages to Manage the Effects of Brand and SelfImage on Brand Evaluations. The Journal of Consumer Marketing, 13(3), 4-18.

Graeff, T. R. (1997). Consumption Situations and the Effects of Brand Image on Consumers' Brand Evaluations. Psychology \& Marketing, 14(1), 49-70.

Gross, R. D. (1987). Psychology: The Science of Mind and Behaviour. London: Edward Arnold Hodder \& Stoughton.

Grubb, E. L., \& Hupp, G. (1968). Perception of Self, Generalized Stereotypes, and Brand Selection. Journal of Marketing Research, 5(1), 58-63.

Hair, J., Black, W., Babin, B., \& Anderson, R. (2010). Multivariate Data Analysis: A Global Perspective (7th ed.). Upper Saddle River, New Jersey, USA: Pearson Prentice Hall. 
He, H., \& Mukherjee, A. (2007). I Am, Ergo I Shop: Does Store Image Congruity Explain Shopping Behavior of Chinese Consumers? Journal of Marketing Management, 23(5/6), 443-460.

Heath, A. P., \& Scott, D. (1998). The Self-Concept and Image Congruence Hypothesis: An Empirical Evaluation in the Motor Vehicle Market. European Journal of Marketing, $32(11 / 12), 1110-1123$.

Hohenstein, N., Sirgy, M. J., Herrmann, A., \& Heitmann, M. (2007). Self-Congruity: Antecedents and Consequences. Paper presented at the La Londe Conference, La Londe les Maures, France.

Holbrook, M. B., \& Moore, W. L. (1982). Using Canonical Correlation to Construct Product Spaces for Objects with Known Feature Structures. Journal of Marketing Research, 19(1), 87-98.

Homans, G. C. (1958). Social Behavior As Exchange. American Journal of Sociology, 63(6), 597-606.

Homans, G. C. (1961). Social Behavior: Its Elementary Forms: Harcourt, Brace \& World.

Homans, G. C. (1974). Social Behavior: Its Elementary Forms: Harcourt, Brace \& World.

Hosany, S., \& Martin, D. (2012). Self-Image Congruence in Consumer Behavior. Journal of Business Research, 65(5), 685-691.

Huang, H. H., Mitchell, V.-W., \& Rosenbaum-Elliott, R. (2012). Are Consumer and Brand Personalities the Same? Psychology \& Marketing, 29(5), 334-349.

Ibrahim, H., \& Najjar, F. (2008). Assessing the Effects of Self-Congruity, Attitudes and Customer Satisfaction on Customer Behavioural Intentions in Retail Environment. Marketing Intelligence \& Planning, 26(2), 207-227. 
Jamal, A., \& Al-Marri, M. (2007). Exploring the Effect of Self-Image Congruence and Brand Preference on Satisfaction: The Role of Expertise. Journal of Marketing Management, 23(7/8), 613-629.

Joshanloo, M., Rastegar, P., \& Bakhshi, A. (2012). The Big Five Personality Domains as Predictors of Social Wellbeing in Iranian University Students. Journal of Social \& Personal Relationships, 29(5), 639-660.

Kerckhoff, A. C., \& Davis, K. E. (1962). Value Consensus and Need Complementarity in Mate Selection. American Sociological Review, 27(3), 295-303.

Klohnen, E. C., \& Luo, S. (2003). Interpersonal Attraction and Personality: What is Attractive-Self Similarity, Ideal Similarity, Complementarity, or Attachment Security? Journal of Personality and Social Psychology, 85(4), 709-722.

Kressmann, F., Sirgy, M. J., Herrmann, A., Huber, F., Huber, S., \& Lee, D.-J. (2006). Direct and Indirect Effects of Self-Image Congruence on Brand Loyalty. Journal of Business Research, 59(9), 955-964.

Lam, S., Ahearne, M., Mullins, R., Hayati, B., \& Schillewaert, N. (2013). Exploring the dynamics of antecedents to consumer-brand identification with a new brand. Journal of the Academy of Marketing Science, 41(2), 234-252.

Landon, E. L. (1974). Self Concept, Ideal Self Concept, and Consumer Purchase Intentions. Journal of Consumer Research, 1(2), 44-51.

Luo, S., \& Klohnen, E. C. (2005). Assortative Mating and Marital Quality in Newlyweds: A Couple-Centered Approach. Journal of Personality and Social Psychology, 88(2), 304-326.

Mai, L. W., \& Ness, M. R. (1999). Canonical Correlation Analysis of Customer Satisfaction and Future Purchase of Mail-Order Speciality Food. British Food Journal, 101(11), 857-870. 
Malär, L., Krohmer, H., Hoyer, W. D., \& Nyffenegger, B. (2011). Emotional Brand Attachment and Brand Personality: The Relative Importance of the Actual and the Ideal Self. Journal of Marketing, 75(4), 35-52.

Malhotra, N. K. (1988). Self-Concept and Product Choice: An Integrated Perspective. Journal of Economic Psychology, 9(1), 1-28.

Mandel, N., Rucker, D. D., Levav, J., \& Galinsky, A. D. (2017). The Compensatory Consumer Behavior Model: How self-discrepancies drive consumer behavior. Journal of Consumer Psychology, 27(1), 133-146.

Markus, H. R., \& Kitayama, S. (1991). Culture and the Self: Implications for Cognition, Emotion, and Motivation. Psychological Review, 98(2), 224-253.

Martin, G. N., Carlson, N. R., \& Buskist, W. (2007). Psychology (3rd ed.). Harlow: Pearson/Allyn and Bacon.

Mazzocchi, M. (2008). Statistics For Marketing and Consumer Research. Los Angeles; London: SAGE.

Montoya, R. M., Horton, R. S., \& Kirchner, J. (2008). Is Actual Similarity Necessary for Attraction? A Meta-Analysis of Actual and Perceived Similarity. Journal of Social \& Personal Relationships, 25(6), 889-922.

Mooi, E., \& Sarstedt, M. (2011). A Concise Guide to Market Research: The Process, Data, and Methods Using IBM SPSS Statistics. Berlin; New York: Springer.

Mooradian, T. A., \& Nezlek, J. B. (1996). Comparing the NEO-FFI and Saucier's MiniMarkers As Measures of the Big Five. Personality and Individual Differences, 21(2), 213-215.

Moore, E. S., Wilkie, W. L., \& Lutz, R. J. (2002). Passing the Torch: Intergenerational Influences as a Source of Brand Equity. Journal of Marketing, 66(2), 17-37. 
Nevid, J. S., \& Pastva, A. (2014). 'I'm a Mac' versus 'I'm a PC': Personality Differences between Mac and PC Users in a College Sample. Psychology \& Marketing, 31(1), 31 37.

Park, S. Y., \& Lee, E. M. (2005). Congruence between Brand Personality and Self-Image, and the Mediating Roles of Satisfaction and Consumer-Brand Relationship on Brand Loyalty. Paper presented at the Asia Pacific Advances in Consumer Research, Duluth.

Pham, M. T. (2013). The Seven Sins of Consumer Psychology. Journal of Consumer Psychology, 23(4), 411-423.

Pounders, K., Kowalczyk, C. M., \& Stowers, K. (2016). Insight into the motivation of selfie postings: impression management and self-esteem. European Journal of Marketing, 50(9/10), 1879-1892. doi:doi:10.1108/EJM-07-2015-0502

Puzakova, M., Kwak, H., \& Rocereto, J. F. (2009). Pushing the Envelope of Brand and Personality: Antecedents and Moderators of Anthropomorphized Brands. Advances in Consumer Research - North American Conference Proceedings, 36, 413-420.

Quester, P., \& Lim, A. L. (2003). Product Involvement / Brand Loyalty: Is There A Link? Journal of Product \& Brand Management, 12(1), 22-38.

Quester, P., Plewa, C., Palmer, K., \& Mazodier, M. (2013). Determinants of CommunityBased Sponsorship Impact on Self-Congruity. Psychology \& Marketing, 30(11), 9961007. doi:10.1002/mar.20662

Ratchford, B. T. (1987). New Insights About the FCB Grid. Journal of Advertising Research, 27(4), 24-38.

Rubin, Z. (1973). Liking and Loving: An Invitation to Social Psychology. New York: Holt, Rinehart and Winston.

Saucier, G. (1994). Mini-Markers - A Brief Version of Goldberg Unipolar Big-Five Markers. Journal of Personality Assessment, 63(3), 506-516. 
Schinka, J. A., Dye, D. A., \& Curtiss, G. (1997). Correspondence Between Five-Factor and RIASEC Models of Personality. Journal of Personality Assessment, 68(2), 355-368.

Schmitt, D. P., Allik, J., McCrae, R. R., \& Benet-Martínez, V. (2007). The Geographic Distribution of Big Five Personality Traits: Patterns and Profiles of Human SelfDescription Across 56 Nations. Journal of Cross-Cultural Psychology, 38(2), 173 212.

Schul, P. L., Pride, W. M., \& Little, T. L. (1983). The Impact of Channel Leadership Behavior on Intrachannel Conflict. Journal of Marketing, 47(3), 21-34.

Sedikides, C. (1993). Assessment, Enhancement, and Verification Determinants of the SelfEvaluation Process. Journal of Personality and Social Psychology, 65(2), 317-338.

Sedikides, C., \& Strube, M. J. (1997). Self-Evaluation: To Thine Own Self Be Good, To Thine Own Self Be Sure, To Thine Own Self Be True, And To Thine Own Self Be Better. In M. P. Zanna (Ed.), Advances in Experimental Social Psychology (Vol. 29, pp. 209-269). San Diego: Academic Press.

Sherry, A., \& Henson, R. K. (2005). Conducting and Interpreting Canonical Correlation Analysis in Personality Research: A User-Friendly Primer. Journal of Personality Assessment, 84(1), 37-48.

Sirgy, M. J. (1982). Self-Concept in Consumer Behavior: A Critical Review. Journal of Consumer Research, 9(3), 287-300.

Sirgy, M. J. (1985). Using Self-Congruity \& Ideal Congruity to Predict Purchase Motivation. Journal of Business Research, 13(3), 195-206.

Sirgy, M. J., Grewal, D., Mangleburg, T. F., Park, J.-O., Chon, K.-S., Claiborne, C. B., . . . Berkman, H. (1997). Assessing the Predictive Validity of Two Methods of Measuring Self-Image Congruence. Journal of the Academy of Marketing Science, 25(3), 229241. 
Stern, B. L., Bush, R. F., \& Hair, J. F. (1977). The Self-Image/Store Image Matching Process: An Empirical Test. The Journal of Business, 50(1), 63-69.

Stokburger-Sauer, N., Ratneshwar, S., \& Sen, S. (2012). Drivers of Consumer-Brand Identification. International Journal of Research in Marketing, 29(4), 406-418.

Swaminathan, V., \& Dommer, S. L. (2012). When Is Our Connection To Brands Like Our Connection To People? Differentiating Between Consumer-Brand Relationships And Interpersonal Relationships. In S. Fournier, M. Breazeale, \& M. Fetscherin (Eds.), Consumer-Brand Relationships:Theory And Practice (pp. 15-29). London: Routledge.

Sweeney, J. C., \& Brandon, C. (2006). Brand Personality: Exploring the Potential to Move from Factor Analytical to Circumplex Models. Psychology \& Marketing, 23(8), 639663.

Wetzel, C. G., \& Insko, C. A. (1982). The Similarity-Attraction Relationship: Is There An Ideal One? Journal of Experimental Social Psychology, 18(3), 253-276.

Winch, R. F. (1958). Mate-selection: a study of complementary needs. New York: Harper.

Wu, E. C., Cutright, K. M., \& Fitzsimons, G. J. (2011). How Asking 'Who Am I?' Affects What Consumers Buy: The Influence of Self Discovery on Consumption. Journal of Marketing Research, 48(2), 296-307. 
Table 1

Trait-to-factor loadings for consumer personality.

\begin{tabular}{|c|c|c|c|c|c|}
\hline & \multicolumn{5}{|c|}{ Rotated component matrix } \\
\hline & Conscientiousness & Agreeableness & Extraversion & $\begin{array}{c}\text { Emotional } \\
\text { Stability }\end{array}$ & Openness \\
\hline 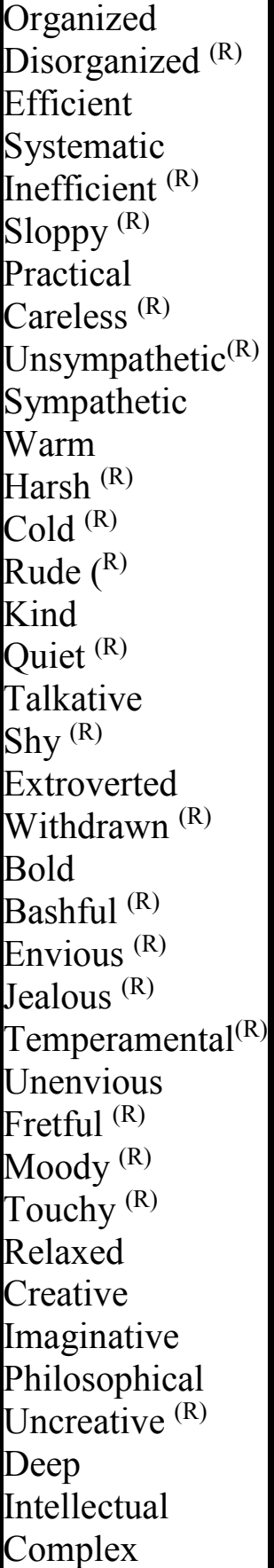 & $\begin{array}{l}.850 \\
.840 \\
.774 \\
.729 \\
.611 \\
.575 \\
.525 \\
.404\end{array}$ & $\begin{array}{l}.766 \\
.729 \\
.696 \\
.672 \\
.598 \\
.561 \\
.549\end{array}$ & $\begin{array}{l}.870 \\
.767 \\
.759 \\
.662 \\
.622 \\
.504 \\
.453\end{array}$ & $\begin{array}{l} \\
\\
.734 \\
.708 \\
.640 \\
.619 \\
.605 \\
.557 \\
.537 \\
.495\end{array}$ & $\begin{array}{l}.739 \\
.708 \\
.699 \\
.601 \\
.600 \\
.477 \\
.404\end{array}$ \\
\hline
\end{tabular}

Extraction Method: Principal Component Analysis.

Rotation Method: Varimax with Kaiser Normalization.

(R) indicates reversed items. 
Table 2

Trait-to-factor loadings for brand personality.

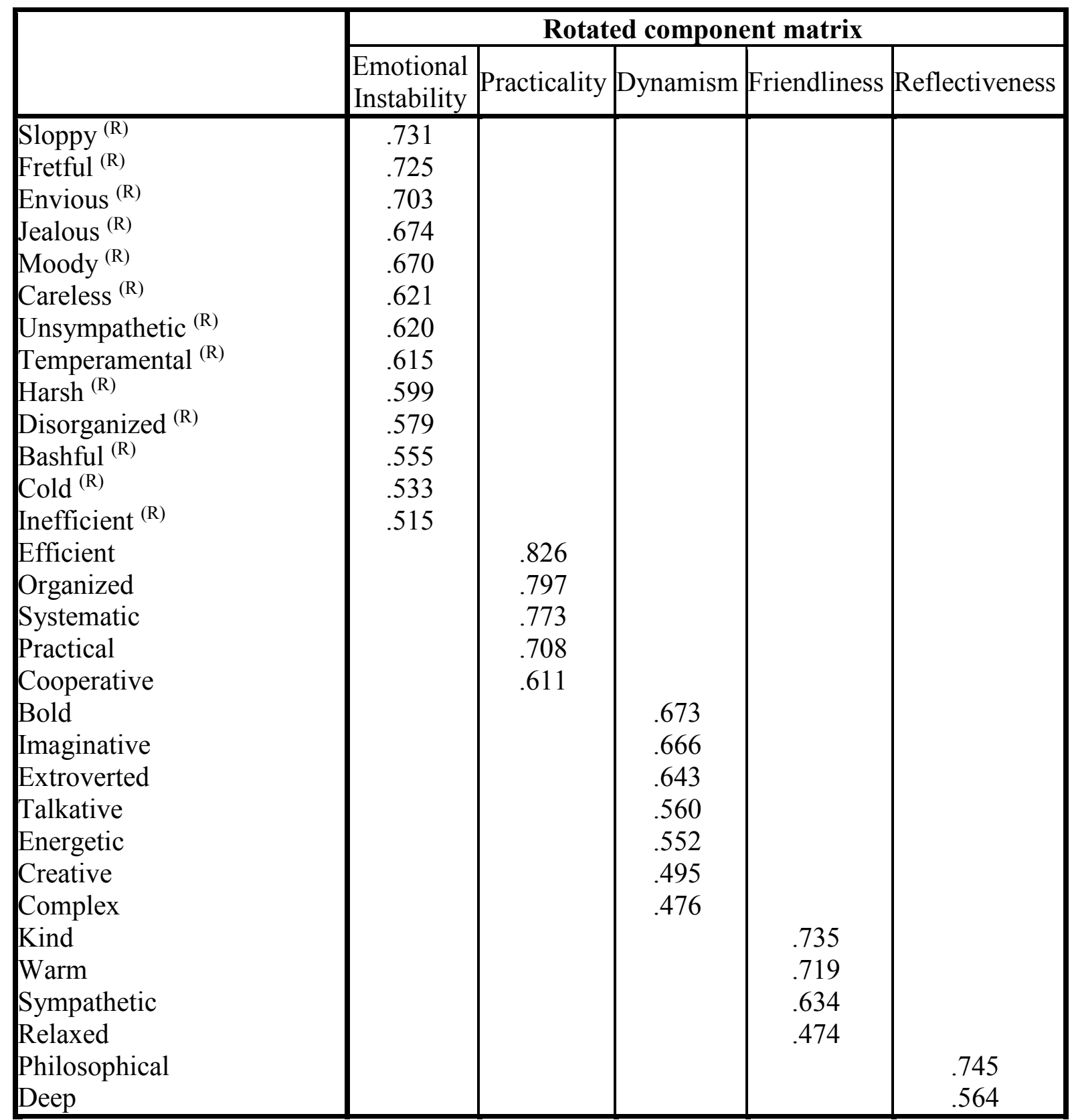

Extraction Method: Principal Component Analysis.

Rotation Method: Varimax with Kaiser Normalization.

$(\mathrm{R})$ indicates reversed items. 
Table 3

Composition of consumer/human personality (HP) and brand personality (BP) factors.

\begin{tabular}{|c|c|c|c|c|}
\hline \multicolumn{5}{|c|}{ Respondents' perceptions of their own personalities (HP) } \\
\hline Conscientiousness & Agreeableness & $\begin{array}{l}\text { Emotional } \\
\text { Stability }\end{array}$ & Extraversion & Openness \\
\hline $\begin{array}{c}\text { Organized } \\
\text { Efficient } \\
\text { Systematic } \\
\text { Practical } \\
\text { Disorganized } \\
\text { Inefficient } \\
\text { Sloppy } \\
\text { Careless }\end{array}$ & $\begin{array}{c}\text { Sympathetic } \\
\text { Warm } \\
\text { Kind } \\
\text { Unsympathetic } \\
\text { Harsh } \\
\text { Cold } \\
\text { Rude }\end{array}$ & $\begin{array}{c}\text { Relaxed } \\
\text { Unenvious } \\
\text { Envious } \\
\text { Jealous } \\
\text { Temperamental } \\
\text { Fretful } \\
\text { Moody } \\
\text { Touchy }\end{array}$ & $\begin{array}{c}\text { Talkative } \\
\text { Extroverted } \\
\text { Bold } \\
\text { Quiet } \\
\text { Shy } \\
\text { Withdrawn } \\
\text { Bashful }\end{array}$ & $\begin{array}{c}\text { Philosophical } \\
\text { Deep } \\
\text { Creative } \\
\text { Imaginative } \\
\text { Intellectual } \\
\text { Complex } \\
\text { Uncreative }\end{array}$ \\
\hline \multicolumn{5}{|c|}{ Respondents' perceptions of their favorite brands' personalities (BP) } \\
\hline Practicality & Friendliness & $\begin{array}{l}\text { Emotional } \\
\text { Instability }\end{array}$ & Dynamism & Reflectiveness \\
\hline $\begin{array}{l}\text { Organized } \\
\text { Efficient } \\
\text { Systematic } \\
\text { Practical } \\
\text { Cooperative }\end{array}$ & $\begin{array}{c}\text { Sympathetic } \\
\text { Warm } \\
\text { Kind } \\
\text { Relaxed }\end{array}$ & $\begin{array}{c}\text { Envious } \\
\text { Jealous } \\
\text { Temperamental } \\
\text { Fretful } \\
\text { Moody } \\
\text { Disorganized } \\
\text { Inefficient } \\
\text { Sloppy } \\
\text { Careless } \\
\text { Unsympathetic } \\
\text { Harsh } \\
\text { Cold } \\
\text { Bashful }\end{array}$ & $\begin{array}{c}\text { Talkative } \\
\text { Extroverted } \\
\text { Bold } \\
\text { Creative } \\
\text { Imaginative } \\
\text { Complex } \\
\text { Energetic }\end{array}$ & $\begin{array}{c}\text { Philosophical } \\
\text { Deep }\end{array}$ \\
\hline
\end{tabular}


Table 4

Canonical solution showing configuration between HP and BP variables.

\begin{tabular}{|c|c|c|}
\hline & $\begin{array}{c}\text { Function } 1 \\
\text { Canonical } \\
\text { Loadings }\end{array}$ & $\begin{array}{c}\text { Function } 2 \\
\text { Canonical } \\
\text { Loadings }\end{array}$ \\
\hline \multicolumn{3}{|c|}{ Predictor variable set (HP) } \\
\hline Agreeableness & .690 & .273 \\
\hline Emotional Stability & .585 & .061 \\
\hline Conscientiousness & .332 & -.275 \\
\hline Openness & .021 & .730 \\
\hline Extraversion & .265 & -.560 \\
\hline \multicolumn{3}{|c|}{ Criterion variable set (BP) } \\
\hline Emotional Instability & .941 & -.206 \\
\hline Reflectiveness & .042 & .825 \\
\hline Friendliness & .269 & .386 \\
\hline Practicality & .199 & .261 \\
\hline Dynamism & .014 & .244 \\
\hline$\%$ variance & 27.8 & 18.4 \\
\hline
\end{tabular}

Note: Canonical loadings reflect the correlation between an observed variable in a set and the synthetic variable of that set (Schul, Pride, \& Little, 1983). They assist in identifying the structure of each synthetic variable (e.g. which observed variables create the synthetic variable) and in this sense, they are similar to factor loadings in EFA (Sherry \& Henson, 2005): the larger the canonical loading of a given variable, the more prominent its role in deriving the canonical function. 